Brit. Heart f., 1967, 29, 638.

CASE REPORT

\title{
Unusual Secondary Tumour of Heart
}

\author{
A. S. ROGEN AND A. D. MOFFAT \\ From the Departments of Medicine and Pathology, Stobhill General Hospital, Glasgow
}

Secondary tumours of the heart are not uncommon. Hudson (1965) gives a full bibliography. The degree and site of involvement, however, are variable. They may occur in widely disseminated neoplasms such as melanomas and lymphoblastomas, or be the result of tumours with a tendency to grow along veins. The latter may extend into the atrium; this appears to be less rare on the right than on the left side of the heart. Willis (1953) quoted Herzog (1917) who described a teratoma of testis which passed through the inferior vena cava to the right atrium and ventricle, and he himself reports that some cases of renal carcinoma and of chondrosarcoma have been described, extending through the inferior vena cava into the right side of the heart and even into the pulmonary arteries. Willis noted, however, that the pulmonary veins were invaded by tumour only rarely. In view of the rarity of invasion of the pulmonary vein by tumour tissue the surprising findings at necropsy in our case prompted us to make this brief report, particularly since in retrospect they probably explain the sudden onset of heart failure not understood by us at the time of its occurrence.

\section{Case Report}

A 38-year-old man was admitted to Stobhill Hospital, Glasgow, on April 21, 1965 with polyarthritis. For some four months he had had recurring pain in the right shoulder and elbow joints and both ankle joints. Over this period he had experienced frequent severe sweats. There had been no significant change in weight. He had a cough which he attributed to a heavy cigarette consumption of up to 40 a day, but he had not noticed anything unusual about the character of sputum. There was striking finger-clubbing and some thickening of the right wrist. There was wasting of the right deltoid muscle. Clinical signs of consolidation were noted in the right upper lobe. The chest $x$-ray film was unusual; it showed two large homogeneous opacities in the upper part of the right lung field (Fig. 1). The lateral view showed that one of them was in the apical segment and the other in the anterior segment of the right upper lobe. The right lobe of the diaphragm was raised.
The diagnosis was made of intrapulmonary tumour of doubtful aetiology, pulmonary osteoarthropathy, and ? carcinomatous neuropathy. $\mathrm{He}$ was anæmic $(\mathrm{Hb}-8.9 \mathrm{~g} .100 \mathrm{ml}$.$) . His sedimentation rate was$ $133 \mathrm{~mm}$. in one hour, and his temperature was raised. His main complaint in the first few days after admission was of pain in the shoulder and wrist joints. The chest $x$-ray appearances prompted a search for a primary focus outside the lungs but none was found in breast, thyroid, kidneys, or alimentary tract. Bronchoscopy was not carried out, because the surgeon, like ourselves, was of the opinion that the lung involvement was almost certainly secondary, and because the patient was extremely distressed and dyspnœic when seen by him four days after admission. He had become dramatically more dyspnoic in these four days, and signs of rightsided heart failure had developed. This we were unable to explain on clinical grounds. His course was steadily downhill. He developed increasing mediastinal and pyramidal tract pressure symptoms and eventually had intractable pain in neck and legs. He died on August $17,1965$.

At necropsy two rounded whitish masses of tumour, each measuring $10 \mathrm{~cm}$. in diameter, occupied the upper and part of the middle lobe of the right lung. One of the masses involved the hilum where two small separate deposits of tumour, average diameter $1.5 \mathrm{~cm}$., were present. The right upper pulmonary vein emerged from tumour which filled its lumen and which extended into the distended left atrium to form a pear-shaped mass, $7 \mathrm{~cm}$. long, whose tip protruded through the mitral valve ring (Fig. 2). Apart from a few thin patches adhering to the surface of the intra-atrial tumour, no thrombus was present in the left atrium. The left ventricle was moderately dilated and the heart chambers on the right side showed considerable dilatation, and there was, in addition, hypertrophy of the right ventricle. No valvular abnormality was present and the myocardium was not invaded by tumour. There were also secondary deposits in the right pleura, the liver, suprarenals, and the brain.

At histological examination lung sections showed an undifferentiated carcinoma with marked cellular pleomorphism, ranging from small round cells to large, often multinucleated, giant cells. Areas of small spindleshaped or oat cells were occasionally seen. Sometimes 638 


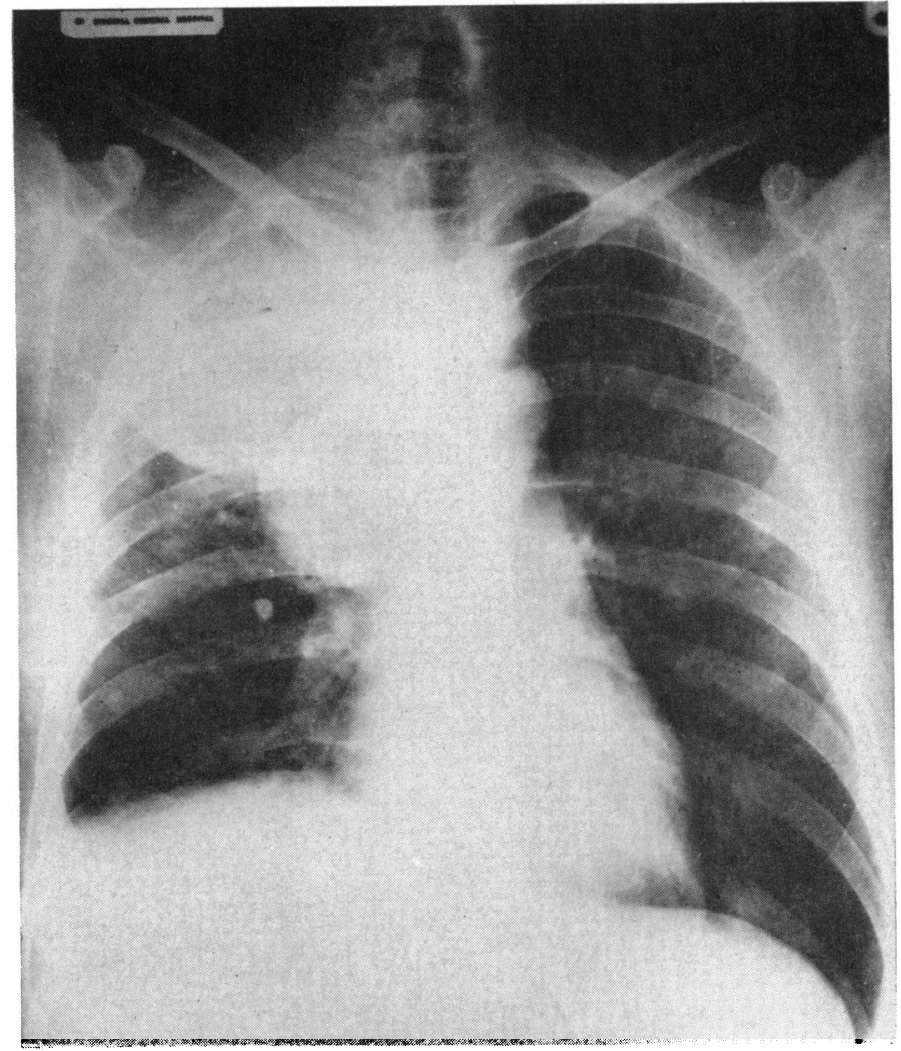

FIG. 1.-Radiograph showing two large rounded opacities in the upper lobe of the right lung.

alveoli, as is seen in aerial spread of lung tumours. The undifferentiated and pleomorphic nature of the tumour was preserved in the intra-atrial extension (Fig. 3) and the secondary deposits in the pleura, liver, and suprarenals. Abortive attempts at adenocarcinomatous transformation were evident in the brain secondaries.

\section{Comment}

R. E. B. Hudson (1966, personal communication) was good enough to examine colour slides of the specimen and remarked on the one hand on the rarity of this condition and on the other on the similarity between this and sarcoma of the atrium and atrial myxoma as far as the macroscopical appearances were concerned. McDonald and Heather (1939), reviewing the published reports on neoplastic invasion of pulmonary veins and left atrium, quoted a case reported by Mead (1932) which was very similar to our own. In this case a large area of the contiguous portions of the upper and middle lobes of the right lung was composed of carcinomatous tissue. This had spread to the heart so that an area, $4 \mathrm{~cm}$. in diameter, consisting of both the overlying pericardium and the myocardium of the right atrium, was invaded by tumour tissue. In addition "a mass of carcinoma tissue originating from the right lung had entered and grown within the right pulmonary vein to the left atrium. The mass had enlarged greatly within the atrium causing a marked dilatation of the atrial wall. The carcinoma tissue had also grown through the bicuspid valves and projected into the left ventricle. The carcinomatous mass in the left atrium so completely filled the cavity that it was difficult to understand how blood could pass from the pulmonary veins into the heart." There was no invasion of the endocardium at any point. This is the only reference we have found to an apparently comparable case. Hanfling (1960) described heart chamber involvement by tumour thrombosis of pulmonary veins following carcinoma of lung, but he gives no incidence. Levene (1964) writes that "carcinoma of bronchus not infrequently involves the heart in a special way by direct spread into the pericardium and where the left lung is the primary site into the left atrium occluding the pulmonary veins en route. Once the heart is infiltrated in this direction endocardial and myocardial deposits follow and malignant 


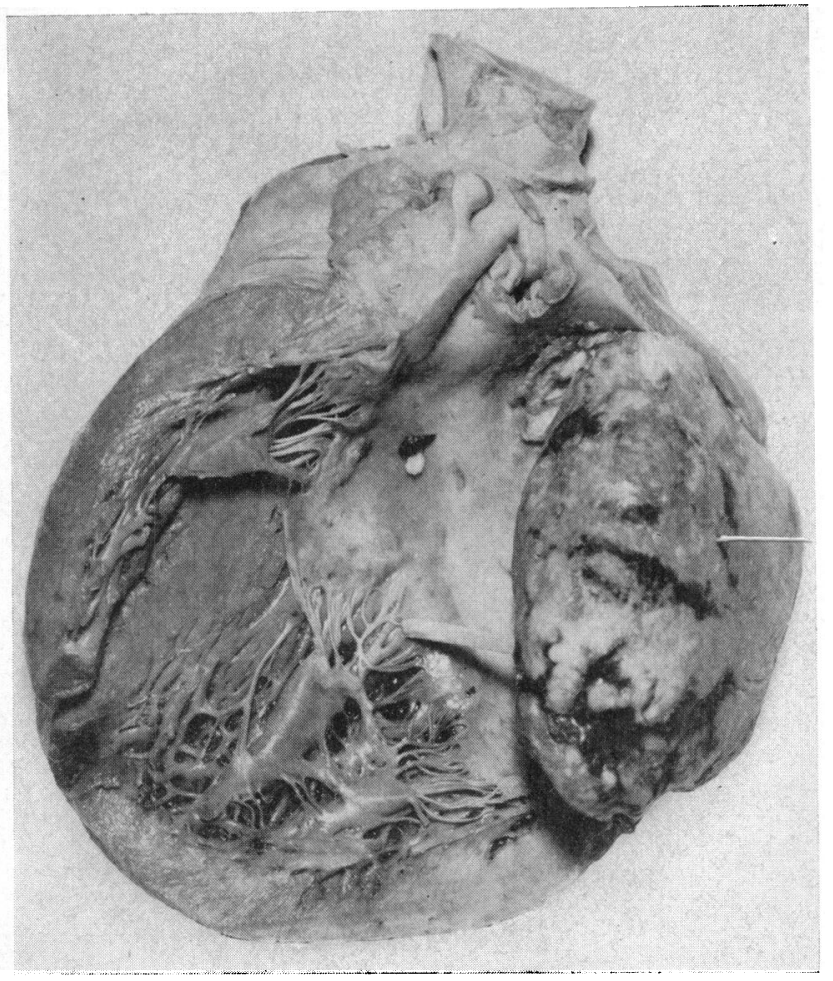

FIG. 2.-Tumour raised, showing that there is no attachment to wall of atrium. $(x 1$.

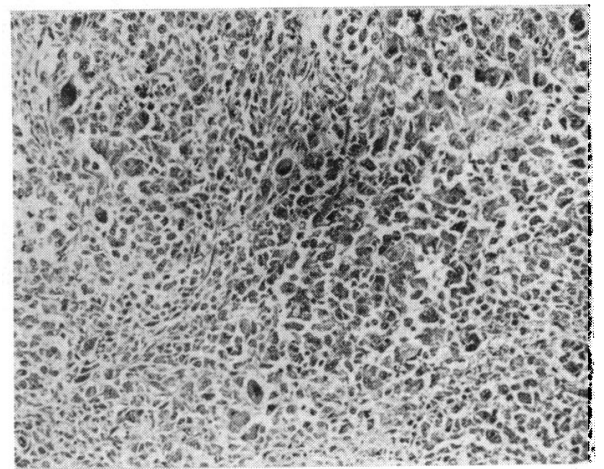

(a)

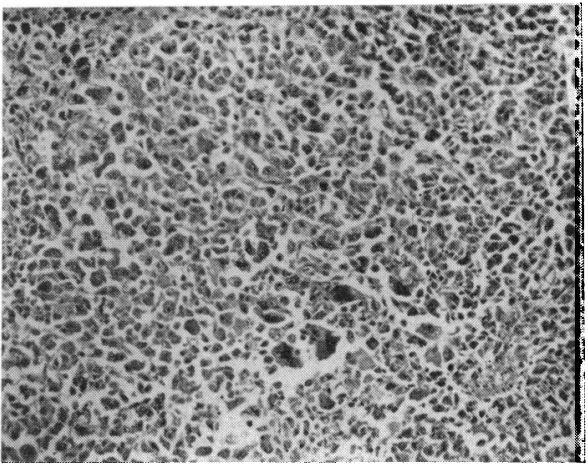

(b)

FIG. 3.-(a) Highly cellular and pleomorphic lung tumour. (b) Intra-auricular tumour showing similarity to $(a) .(\times 100$. pericarditis is almost invariably present in some degree." No figures are given to indicate the frequency. Our case differed in that the right lung was the seat of the primary tumour, and even at the advanced stage of growth of the intra-atrial tumour there was no other evidence of heart involvement. Gould (1953) quotes Woll and Vickery (1947) as suggesting that a diagnosis of heart tumour should be considered with the development of unexplained and intractable cardiac failure. The comparatively rapid onset of failure in our case, which did indeed prove intractable, was not understood by us at the time. In the light of the necropsy findings such failure became clearly explained.

\section{Summary}

A case is reported of unusual spread of carcinoma of the bronchus into and along a pulmonary vein from the right lung. The tumour spread into and filled the left atrium and eventually entered the mitral ring. Right-sided heart failure of rapid onset, not at the time understood, was probably explained by these findings.

We are most grateful to Mr. P. Waldie, Medical Photographer, for his assistance and advice.

\section{References}

Gould, S. E. (1953). Pathology of the Heart. Charles C. Thomas, Springfield, Illinois.

Hanfling, S. M. (1960). Metastatic cancer to the heart. Review of the literature and report of 127 cases. Circulation, 22, 474.

Herzog, G. (1917). Quoted by Willis (1953).

Hudson, R. E. B. (1965). Cardiovascular Pathology, vol. 2, p. 1596. Edward Arnold, London.

Levene, A. (1964). Secondaries in the heart. Med. Wld (Lond.), 101, 135.

McDonald, S., Jr., and Heather, J. C. (1939). Neoplastic invasion of the pulmonary veins and left auricle. f. Path. Bact., 48, 533.

Mead, C. H. (1932). Metastatic carcinoma of the heart secondary to primary carcinoma of the lung. F. thorac. Surg., $2,87$.

Willis, R. A. (1953). Pathology of Tumours, 2nd ed. Butterworth, London.

Woll, E., and Vickery, A. L. (1947). Quoted by Gould (1953). 